\title{
Consumer Awareness of Palm Oil as an Ingredient in Food and Non- food Products
}

by Aguiar, L.K., Martinez, D.C. and Caleman, S.M.Q.

Copyright, Publisher and Additional Information: This is the author accepted manuscript. The final published version (version of record) is available online via Taylor \& Francis Please refer to any applicable terms of use of the publisher.

DOI: http://dx.doi.org/10.1080/10454446.2017.1266559

Harper Adams

University 


\title{
Consumer Awareness of Palm Oil as an Ingredient in Food and Non-food Products
}

\author{
Luís Kluwe Aguiar (corresponding author); Dudley C. Martinez and Silvia M.Q. \\ Caleman
}
Harper Adams University - Department of Food Science and Agri-food Supply Chain Management, Edgmond, Newport, TF10 8NB, England. Tel. 00441952820280
E-mail: Ideaguiar@harper-adams.ac.uk

\begin{abstract}
Vegetable oil crop production has increased faster than other food or industrial crops in recent years. Palm oil which is widely grown in tropical areas has become the most internationally produced and traded oil with detrimental effect to the natural environment and the sustainability of producing communities. The general perception of the industry conveys a negative image to consumers. To better understand the extent consumers' perception of palm oil products would inform stakeholders in the sector 25 one-to-one interviews using the means-end laddering technique (Olson and Reynolds, 2001) were carried out to elicit attributes which led to the establishing of value perceptions of products containing palm oil. Pal production practices have elicited negative Environmental Concern Values regarding the availability of resources for future generations. Environmental consciousness seems to be an important attribute marketers should take into account when both developing and promoting products. However, consumers' perception of palm oil as a product ingredient was regarded as minimal. Palm oil was perceived as being a more natural product whose naturalness could be exploited regarding 'physical wellbeing' values leading helping consumers achieve a health life and higher selfstem.
\end{abstract}

Key Words: palm oil, sustainability, means-end chains, marketing strategies

\section{Introduction:}

In the last decades, vegetable oil crops have expanded at the expense of other food and non-food crops. It is amongst the top seventeen oils and fats used for human, animal feed and the oleochemical industry (Gunstone, 2011). In the process, palm has become the dominant oil crop produced in tropical areas of Asia, Africa and Latin America (Wicke et al., 2011). Nonetheless, much of the crop's expansion has occurred in detriment to the natural environment and at a high social cost to rural communities (Rist et al., 2010).

The palm oil's versatility has enabled its widespread use since $80 \%$ of it is consumed as edible and $20 \%$ as non-edible (Basiron and Kook-Weng, 2004). In the food sector, when compared to other unsaturated oils, the oil's main advantage comes to light in deep frying preparations owed to it resisting oxidation at high temperatures. 
The potato chips and crisps industry uses refined red palm oil also to give a more desirable colour to the final product (Corley and Tinker, 2003; Gee, 2007). Palm oil also enters food formulations in bakery containing butter, margarines and in ghee. In the production of confectionaries, chocolate-flavoured confectionary and cake coatings the oil's mid-fraction (liquid/solid state) characteristics are ideal for the replacement of up to $30 \%$ of fats such as cocoa butter with substantial cost gains (Corley and Tinker, 2003). Especially in new product development, the food industry routinely includes palm oil in preparations of reduced fat spreads and ice cream; as a replacement for butter fat in dairy products including cheese, coffee whiteners, whipped cream; and in mayonnaise and salad dressing. It has a widespread use in ready chilled and frozen meals, nutraceuticals' formulations; coconut milk powder, and in micro encapsulation (Basiron and Kook-Weng, 2004; Gunstone, 2011).

The non-edible applications of palm oil are also significant due to its high added value. Palm oil can be used directly in polyurethanes; printing ink; engineering thermoplastics; fuels and drilling mud (as a non-toxic substitute for diesel), or indirectly. Indirectly, it works as oleochemicals in lubricants; personal care products (these include the whole range of cosmetics, soaps and toiletries); as fatty acids, fatty esters, fatty alcohols, fatty nitrogen and glycerol. Moreover, palm-based olechemicals of food grade can be used to coat food wrapping paper replacing the banned polyethylene coated brown paper; agrochemicals; surfactants used as inert ingredients in pesticide formulations-wetting and dispersing agents; and in paints as emulsifier; solvent; carrier, and diluent (Basiron and Kook-Weng, 2004; Gunstone, 2011). More recently, palm oil production has also contributed to the food-fuel debate issue as strong source of bio-fuel.

Despite its ubiquitous presence in today's consumption, palm oil production has been linked to high rates of environmental degradation (Rist et al., 2010). Large multinational palm producing enterprises are often accused of causing deforestation of the rain forest which affects the biodiversity and the natural balance of the surrounding environment which lead to the extinction of both vegetable and animal species. Hickman (2009) mentioned about the expansion of palm oil not only causing the loss of the forest itself, but also being responsible for the emission of huge quantities of greenhouse gas. Generally, the impact of the release of the greenhouse gas increases the risk for livelihood of endangered species especially in Malaysia and Indonesia especially through practices slash and burn of the natural forest and from planting oil palm on peat lands. When a palm plantation is first established; which, these bad agricultural practices have been estimated to release from 3,750 to 5,400 tonnes of carbon dioxide over a period of 25 years (Block, 2009).

In addition, the industry's bad reputation is often associated to the exploitation of labour and the disregard of basic human rights, especially in cases of land grabbing reported in Indonesia (Gellert, 2015). Furthermore, both North American and European consumers have raised their concerns about the palm industry's unsustainability since it is responsible with high levels of pollution from practices and processes (Gunstone, 2011). Thus, it is currently one of the most controversial industries worldwide regarding social, economic and ecological dimensions.

In this context, there is a need to better understand the extent consumers regarded the presence of palm oil in some FMCG products whether as problematic or not. 
Such a study would also elucidate the degree to which the presence of palm oil in some products would influence consumers in their decisions. Therefore, this study was intended to provide an insight into the consumers' awareness regarding the presence of palm oil as ingredients in many edible and non-edible products sold in the main stores and supermarkets in the UK.

\section{Methodology}

The Means-End technique was used as it implies that the consumers' subjective product perception is established by associations between product attributes and more abstract, more central cognitive categories such as values, which motivate behaviour and create interest for product attributes. A product attribute per se has little or no importance or relevance to consumers. Instead, attributes have meaning and value for consumers largely in terms of the consequences they are perceived to bring about (Olson and Reynolds, 2001). The end-consequence in a means-end chain is often a personal goal or a life value consumers are striving to achieve. This technique approach facilitates the understanding of complex behaviour and it has successfully been used in food research (De Pelsmacker and Janssens, 2007; Bredahl, 2003 and Grunert et al., 2004). In-depth, one-to-one laddering interviews were carried out from a randomised sample of 25 of higher education in the UK. In adopting the Means-End Chains technique, information was gathered regarding the consumers' perception of specific given attributes concerning the presence of palm oil in products. Linkages between the declared (brand name, promotion recall and past experience) products' attributes (the means), the respondents' consequences elicited from those attributes, and the personal values (the ends) were constructed around ladders (Olson and Reynolds, 2001) using a LadderingMap Software.

A total of six edible and non-edible FMCG products which contained palm oil as ingredient were selected from a range of food retailers catering for different consumers' profiles: niche market food retailers, mains stream multiples and discount stores. The products' label information were scrutinised to assure the presence of palm oil (palm oil or palm kernel oil) and palm components (ethylhexyl palmitate derived from the palmitic acid which is mainly used as a thickening agent, and palm kernelate used as a salt commonly used for manufacturing soaps) in their composition. This helped to verify whether consumers were aware of the presence of palm oil as an ingredient or not, and to check which attributes consumers most favoured in their purchasing decision.

The product selection also considered products which would be frequently consumed by both genders. The products were grouped in three categories: chocolates, cosmetics and crisps. For each of the categories, two brands were chosen: a chocolate coated waffle biscuit and a milk chocolate bar; a soap from an established cosmetics' niche retailer and a branded soap; and two brands of potato crisps.

The interviews were organised in two phases. Firstly, the respondents were shown cards containing a laminated colour print of the labels for each individual product. In doing so the cueing of the initial attributes was facilitated. Within each category, and to elicit distinctions between brands, the respondents were free to select the product which they were most familiar with or the one which they frequently consumed. At 
the end of the interviews, the respondents were asked whether they were aware of the presence of palm oil as an ingredient in all the products or not. This led to the second phase of the interview which focused specifically on palm oil which consisted of seven cards containing written statements regarding palm oil attributes or characteristics obtained from the data gathered from the literature review: (1) semi solid texture, (2) versatility (edible, non-edible); (3) source of employment, (4) unsustainable, (5) trans fatty acid free, (6) content of unsaturated fat and (7) content of antioxidants. In order to facilitate the analysis and because characteristics 5, 6 and 7 all related to fat content the responses were grouped under the attribute "fat content".

The average time employed for conducting the interviews was forty minutes. For all the interviews the authors used a digital recorder. All interviews were later transcribed and the key attributes or emblematic words that would help with the laddering technique were identified.

\section{Results and Discussion}

The data collated served to build ladders for each of the respondents which were later consolidated onto a laddering map. The most relevant meanings were extracted from each interview and plotted according to Attribute/Consequence/Value (A/C/V) levels. To avoid broad coding, concepts that expressed similar context were grouped within one same content code. For example, "image" in the Hierarchical Value Map for the 'category chocolate', represented a summarization of other meanings such as 'takes care of my body', 'look slim and beautiful' or 'don't gain weigh'. The content codes were assigned to each of the products and to 'palm oil' as seen from Table 1.

The numbers on brackets, for example (38) Family Life, represent the scores given by the LadderingMap for generating the implication matrix, which linked all the elements to be mapped. The implication matrix provided the number of times each element led to each other element; thus it represented both direct and indirect relationships within the basic elements $\mathrm{A} / \mathrm{C} / \mathrm{V}$ ladder. The matrix also enabled the quantitative analysis of the laddering data that was previously classified into codes. Once the program generated the implication matrices, an aggregate Hierarchical Value Map for each product category was elaborated. Two cut-off values which determined the associations between two codes were chosen.

Regarding palm oil, the attributes assessed were: Semi solid texture, Fat content, Versatility, Source of employment and Unsustainable. These were selected by the authors based on the most relevant characteristics associated to palm oil as a result of the review of the literature. The aggregate Hierarchical Value Map for palm oil is represented in Figure 1. A cut-off level of 3 was chosen and the measure of variance accounted for $70 \%$ of the responses. It is suggested to use cut-off points equal to $5 \%$ of the sample size (Gengler and Reynolds, 1995) and to represent a minimum of $70 \%$ of the associations on the map. In the case of palm oil, a link was drawn between two content codes provided that at least three people had mentioned the content codes as either a direct or indirect relationship. According to Olson and Reynolds (2001), the amount of connections or associations represented on the HVM, are referred to as a measure of variance. In order to help with the 
understanding of this HVM, the attributes were analysed following the order in which each of them were scored by the LadderingMap Software, starting from Unsustainable (scored with the number 1 as it got the highest number of associations) followed by Source of Employment (2) Versatility (3), Fat Content (4) and finally Texture 5 (Figure 1).

Table 1 - Content codes for Palm Oil

\section{Content codes for Palm oil}

\section{Values}

(30) Healthy life

(31) Better life (economic welfare)

(32) Concern for the environment

(33) Accomplishment

(34) Loyal consumer

(35) Threat for future generations

(36) Self Esteem

(37) Social values

(38) Family life

(39) Human welfare

(40) Feel good with self

\section{Consequences}

(6) Physical well being

(7) Generates income

(8)

(9) Image

(10) Quality

(11) Less waste

(12) Planning future

(13) Cooking results

(14) Happiness

(15) Natural product

(16) Enjoyment of food

(17) Impact on food security

(18) Reluctant to consume

(19) Ecological damage

(20) Product preference

(21) Inappropriate

agricultural management

(22) Not as important as

generation of employment

(23) Research founding

(24) Immediate acceptance

(25) Comfortable with product

(26) Save money

(27) Potential cheap substitutes

(28) Not relevant

The characteristics associated to the unsustainability of palm oil have provoked a negative reaction for the majority of respondents who expressed that unsustainability negatively influenced their perception towards products or goods as it directly had an effect on their Environmental Concern Values. In addition, respondents concurred that the negative impact from unsustainable practices threatened the availability of resources for future generations which, on its turn, directly affected the future of the industry in achieving a sustainable development as seen from Figure 1. 
An analysis of some of the individual ladders was considered important to improve the understanding of the associations created. In view of this, the chains unsustainable - environment concern and unsustainable - threat for future generations have been extracted from Figure 1 and are shown in Figure 2.

As for the means-end chain unsustainable - threat for future generations, a considerable group of respondents agreed that the activity was deemed unsustainable as a result of inappropriate agricultural management. Respondents who elicited this content code focused their concern on the vast extension of land already cultivated as well as the rapid expansion of the crop. As a result, that led to the local population having less availability of land for other food crops which was considered an important issue by the respondents thus agreeing with the findins of Gellert (2015). The value 'threat for future generations' was elicited seven times and took the sixth position within this category. The respondents indicated there was a need for stopping the current levels of deforestation and cultivation of oil palm on natural forest land as it was a threat for future generations. Moreover, palm plantations which replace food crops have also implications regarding food security, thus acting as a threat.

One respondent commented: 'I do not understand the tendency of increasing the cultivated land of oil palm. Despite of having high yields and being a source of employment, I believe that practicing monoculture increases the risk of the availability of other agricultural food goods, especially in developing countries'. This statement served to demonstrate the level of concern that some of the respondents had with regards to the negative impact that increasing oil palm plantations could have on food security. Moreover, respondents also expressed being worried about the negative consequences that future generations could experience as a result of less availability of food products. The association between the elements food security and threat for future generation was strongly linked among respondents as also shown in Figure 2. These value perceptions are fundamental for stakeholders of the palm industry because they are intrinsic to the triple bottom line approach.

In the chain unsustainable - environment concern, the main indicator to assess palm oil's unsustainability was 'ecological damage'. Figure 2 depicts that there was a strong association between these two elements of the chain with 'environment concern' being elicited eight times and scored in place 31 in the aggregate map. However, within the category of values, it took the third position according to the number of direct or indirect associations given by respondents. The issue of exploitation in palm production was associated to 'ecological damage' (high levels of deforestation and its impact on biodiversity). Nonetheless, the majority of the respondents did not regard palm production's unsustainability as an issue which affected human rights of the rural poor. 
Figure 1 - Hierarchical Value Map for Palm Oil

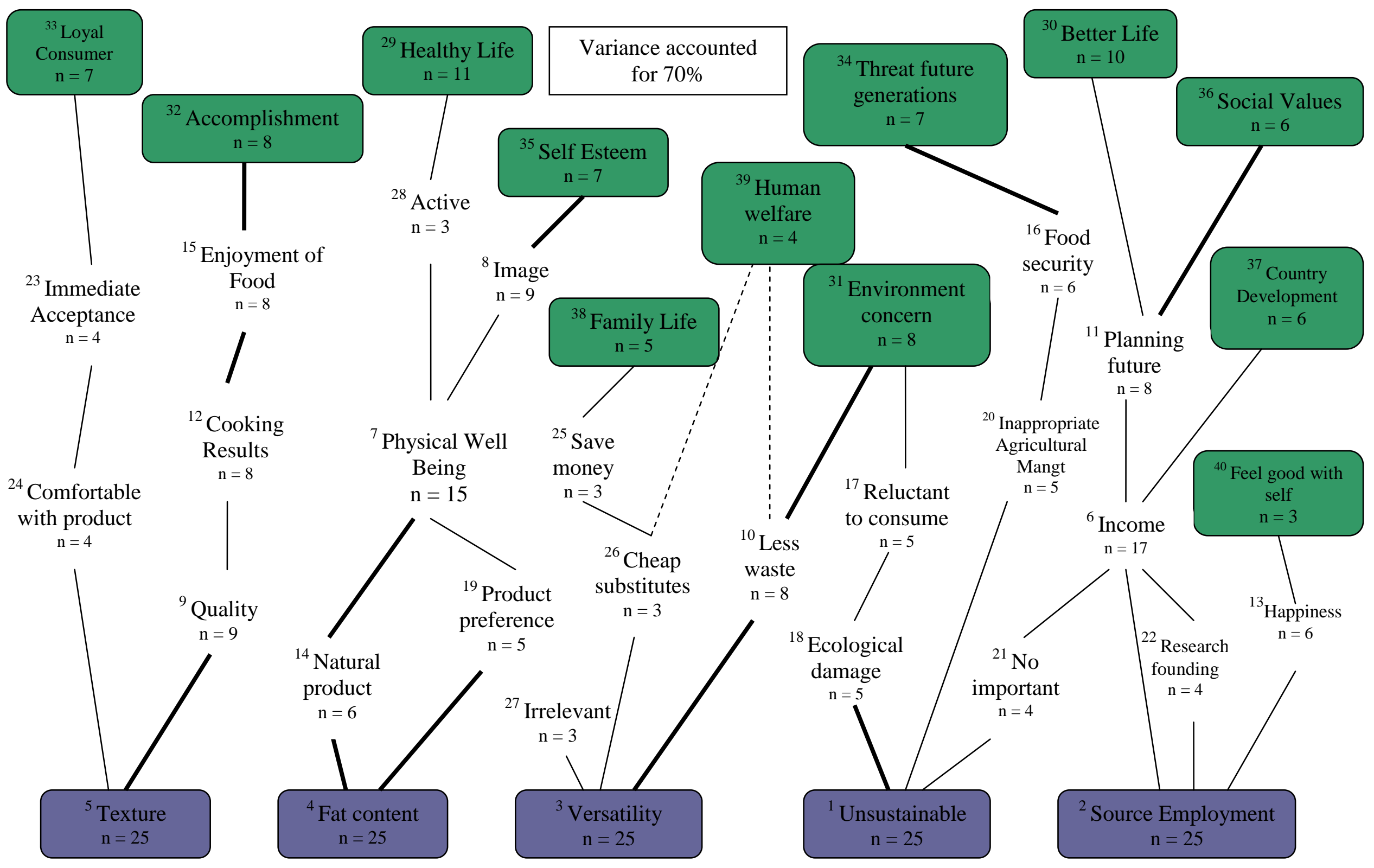




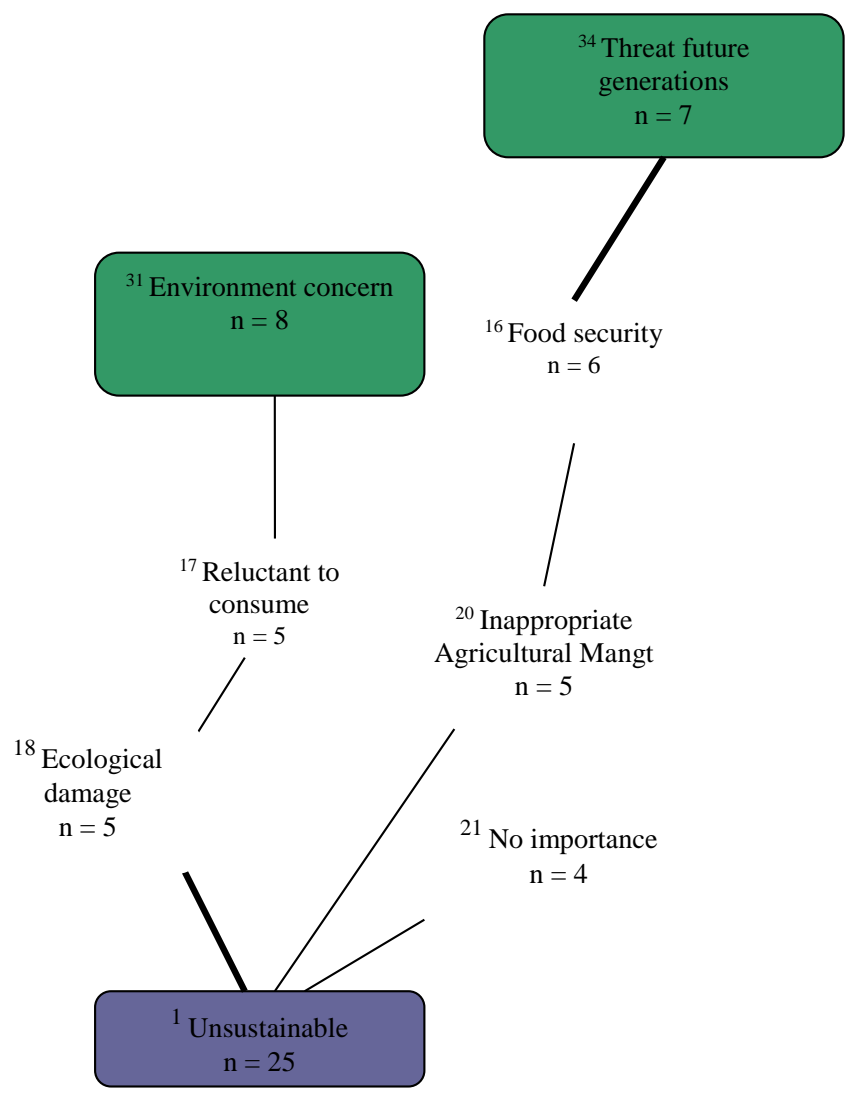

The link between ecological damage and reluctance to consume, as seen from Figure 2 above, depicts the perception of some respondents towards the possibility to stop consuming products which use palm oil as ingredient. Respondents stated that by doing so they contributed to the taking care of the environment. Hence, this is an important finding for those acting along the palm oil supply chain as there is the clear need to provide proof of its commitment either, by stopping practices of exploitation, or improving the sustainability of these practices in order to avoid more forest destruction and further loss of endangered species.

The link between unsustainable - no importance, as shown in Figure 2, represented the association given by a minority of respondents who considered that palm oil's unsustainability to be less relevant when compared to palm oil as a source of employment, which was the next attribute to be analysed. Yet, in Figure 3, the respondents found the attribute 'source of employment' was an important characteristic that led them to reinforce their understanding of the values towards the socio-economic development in palm producing countries. On the one hand, the respondents agreed that the rate of employment generated by the palm oil industry allowed local people to achieve better conditions of life and it also contributed to the development of producing countries.

On the other hand, the respondents also admitted that purchasing products which had palm oil made them feel rewarded as they believed that they were helping to 
develop those people working directly or indirectly for the industry. The means-end chains resulted from the attribute 'source of employment', presented in Figure 3 shows 'generation of income' as the main indicator when assessing source of employment since it was both directly and indirectly linked to that attribute. According to the amount of associations linked to each value, 'achievement of better life' $(n=10)$ was the most important value to be fulfilled when assessing palm oil as a source of employment. Moreover this value was the second most elicited on the aggregate map. In addition, the satisfaction of helping people in palm oil producing countries, as well as the contribution of the industry in the development of countries $(n=6)$, were also important values to be reinforced in respondents' perception at the moment of evaluate generation of employment.

\section{Figure 3 - M-ECs related to the attribute "Source of Employment"}

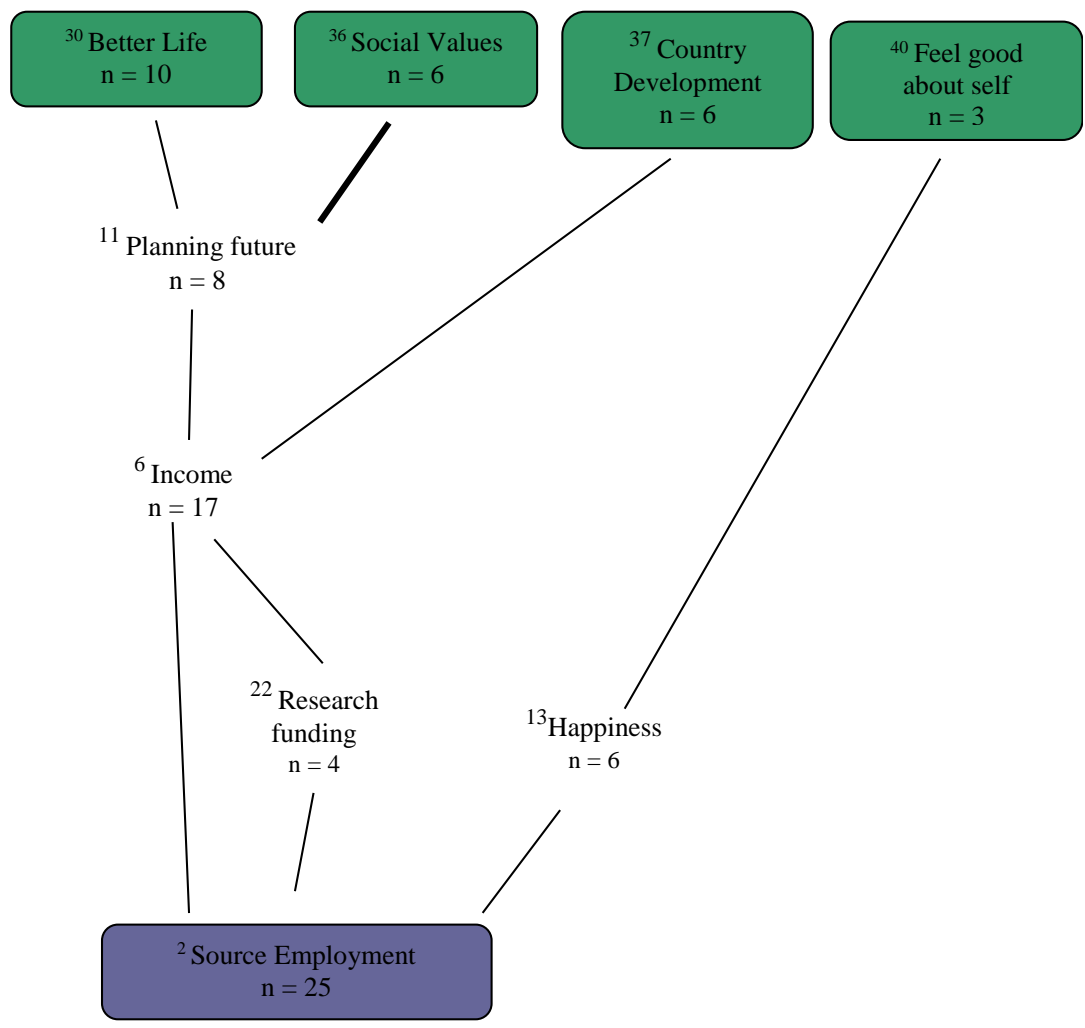

The above means-end chain indicates that the respondents have directly associated 'source of employment' to 'generation of income', and associations were also made regarding the palm industry having attracted some research founding. It has transpired that funds for the agricultural research had allowed for the improving of efficiency in production and the quality of palm oil. Improvements along the chain have resulted in the current boost of the palm oil trade contributing to the development of producing countries. For example, the palm oil industry in Malaysia might have helped alleviate poverty in that country (Rist et al., 2010). One respondent also perceived important the role of the industry with regards to the generation of employment in Indonesia: 'I support 100\% what palm oil industry has done in Indonesia as I have witnessed how the industry has contributed to the 
development, not only of the local people, but the country in general. There are schools, roads; hospitals in places were two decades ago there was nothing. It has definitively helped with the economic growth of the country'.

Figure 4, below, depicts the means-end chains regarding the attribute 'versatility'. Such an attribute has been referred to the capacity of the palm oil to generate a great diversity of products for edible and non-edible purposes. In addition to its industrial use, oil palm cultivation provides several benefits in plantations such as: the waste from the empty fruit bunches being used for mulching, the effluent from palm oil milling used as fertilizer, trunks and fronds also used as mulch. Palm oil wastes could also be considered as source of renewable energy (Pye and Bhattacharya, 2013). In fact, it was the possibility of taking advantage of the whole plant what motivated respondents to perceive the versatility of palm oil as an attribute that could reinforce their values towards a sustainable development through its socio economic and ecological pillars.

As also depicted from Figure 4, there are strong associations linking the attribute with 'less waste' and with 'environment concern' demonstrating that the majority of respondents $(n=8)$ perceived that there was an efficient use of waste from oil palm, either as organic fertilizer or as renewable energy source. Such good practice might contribute to reduction of the pollution levels related to bad agricultural and processing practices within industry. Moreover, a high number of respondents $(n=5)$ asserted they could enhance their family income position by saving money when purchasing cheaper and healthier products obtained from the vast industrial applications of palm oil. 


\section{Figure 4 - MECs resulted from the attribute Source of Employment}

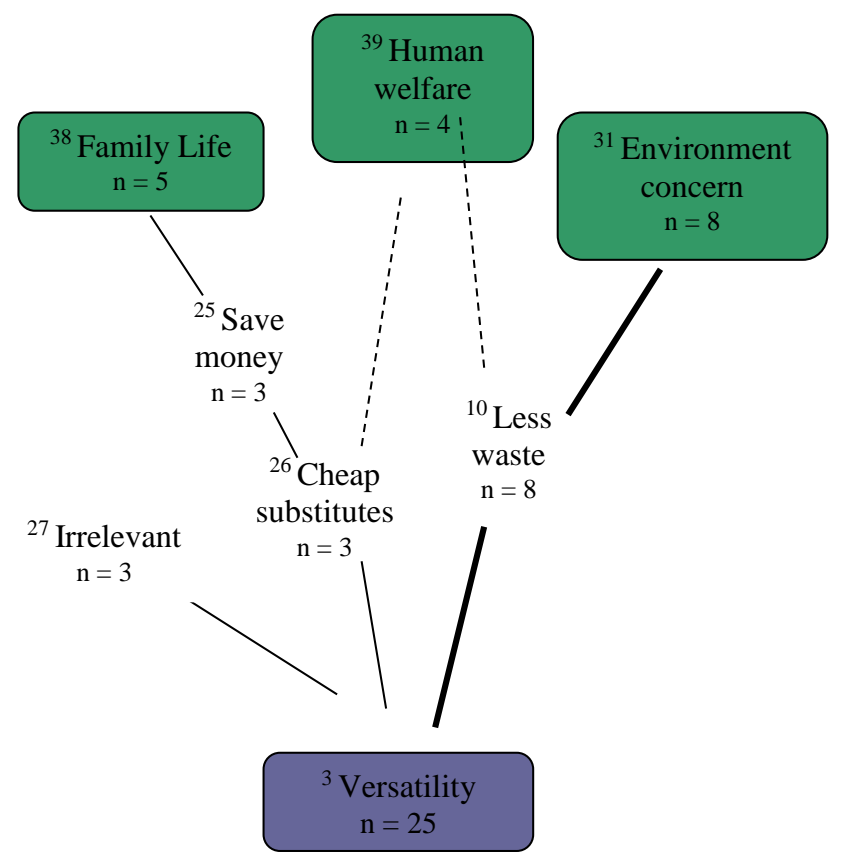

Following that, as a result of the elicited attribute 'versatility' both consequences 'cheap substitutes' and 'generation of less waste' were further elicited in order to obtain a better picture of what the respondents were considering at the time of the interviews. As a result, the two derived consequences 'cheap substitutes' and 'save money' could be understood as the respondents achieving a relative improvement in their income through the availability of cheap substitutes as well as for them to live in a less contaminated environment. The latter is thought to be the case of achieving efficient management of waste by-products derived from the exploitation of the oil palm products. Finally, a minority of the respondents did not consider the attribute 'versatility' to be important because when purchasing a product containing palm oil they ended up assessing the product itself and not the raw materials as ingredients in the manufacturing process. Despite this, the respondents provided a good insight into consumption habits of the respondents.

The means-end chain resulting from the attribute 'fat content' is depicted in Figure 5. Regarding 'fat content', this attribute grouped three different but related palm oil characteristics: trans-fatty acid free (responsible of bad cholesterol), high content of unsaturated fat $(50 \%)$ and content of antioxidants specifically vitamin $A$ and vitamin $E$. The fat content have elicited the notion that the respondents could achieve a healthier and longer life as well as 'maintain their sense of worth'.

When grouping the attributes fat and antioxidants for palm oil as one, the respondents ranked palm oil as a 'more natural product'. In addition, the attribute 'trans fatty free' could lead respondents to an immediate preference for palm oil. As seen in Figure 5, these two associations were elicited by many respondents as illustrated by a thicker line. In addition, both associations were directly linked to 'physical wellbeing' which was the main indicator perceived by respondents when 
evaluating fat content. It can also be depicted from Figure 5 that respondents related 'a more natural product' to a greater benefit for their 'physical wellbeing'. This relationship is demonstrated by the thicker line linking both elements of the chain.

'Physical wellbeing' grouped benefits such as 'to be less likely to develop high blood pressure 'or' heart diseases' and 'to reduce the content of bad fat on their bodies 'resulting in 'athletic figures'. Whereas the first two benefits could have allowed respondents to be 'more active and productive' throughout their life, thus achieving a healthier and longer life, the third could be associated to the respondents' selfimage. Respondents agreed that having an athletic body, looking good, slim and beautiful contributed to them feeling more confident, which increased their selfesteem.

Finally, regarding the respondents cooking habits, those who liked cooking and did it frequently agreed that they preferred using mainly vegetable oils, which did not affect the taste or smell of the food. When cooking for other people, they appreciated when people enjoyed eating, and felt highly rewarded when they received compliments. These associations are demonstrated in the aggregate HVM through the MECs regarding the attribute 'texture'. However, the majority of respondents admitted they had not used palm oil in cooking but showed willingness to trying it.

Figure 5 - M-ECs resulted from the attribute "Fat Content"

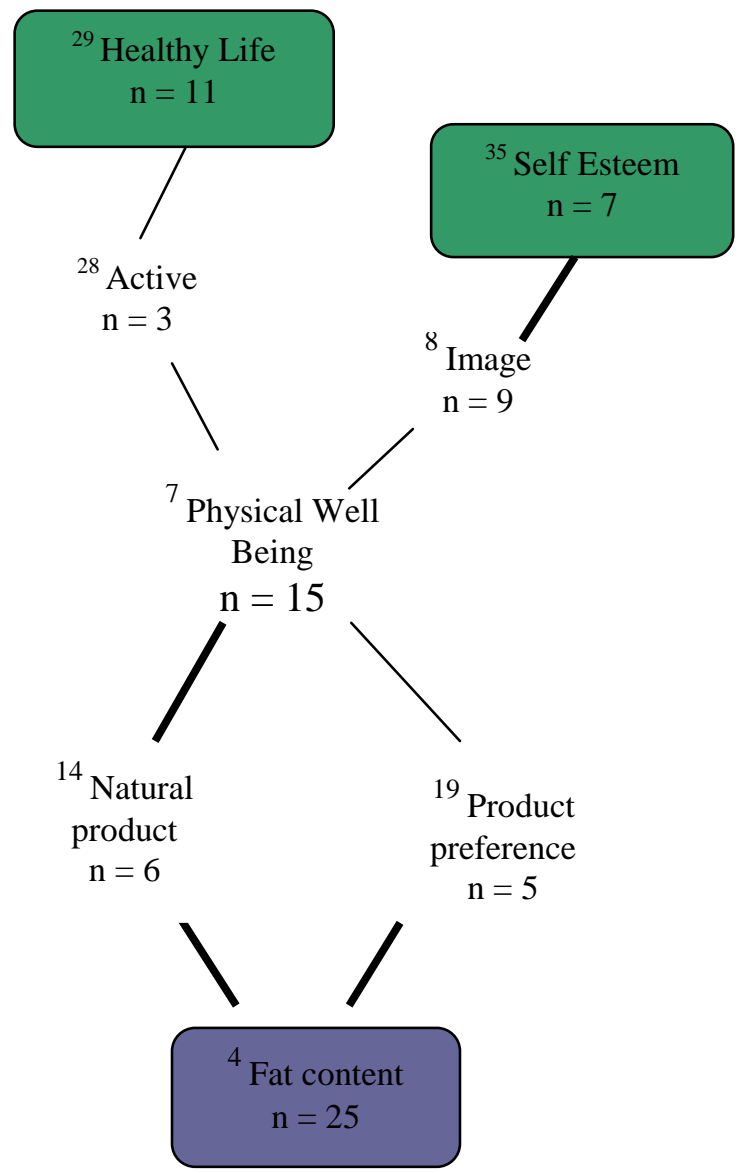




\section{Conclusions}

The findings have revealed that when the respondents were elicited, they regarded the social and environmental concern values to be high. The ever increasing environmentally driven consciousness consumers have are important aspects for palm producers, processors, traders and retailers to bear in mind when bringing products to market which might have palm oil as ingredient. New Product Development professionals and marketers ought both to take into account the sustainability dimension when both developing and promoting products. However, the attributes, 'unsustainability' and 'source of employment' showed how polarised and controversial palm oil has become. On the one hand, it is clear the negative image the palm oil sector has had on the environment and on sustainable development or remote tropical areas. On the other hand, in producing countries there is the perception that the industry has positively influenced the improvement of local people's lives and economic development. Nevertheless, the respondents perceived that the present rate of exploitation of natural resources in detriment of the future generations is not sustainable.

Despite the general knowledge that the respondents acting as consumers have on the impact of the palm oil industry, it is clear that they would not stop consuming products with palm oil as ingredient. It could be concluded that the respondents tended to be ignorant about the ingredients in the products consumed. As a result, despite the eliciting of environmental consciousness-related attributes, in FMCG when the amount of time allocated for a purchase decision is limited, consumers lack of a greater awareness of what the ingredients might be. Conversely, the respondents ranked palm oil as a more natural product, which could lead on to an immediate preference for the product. The naturalness notion embedded in the product could also be exploited regarding the 'physical wellbeing' value leading on to health life and higher self-stem.

This study attempts to throw some light into the complex interactions between more general sustainability agendas and actual consumer values. It could be concluded that, regarding the act of consumption, the perception of palm oil as ingredient being minimal helps to endorse the continuation of the palm industry to further expanding. The respondents' perception indicate that environmental and sustainability-related governance in the palm supply chain has been relatively effective in addressing some of the more detrimental practices in the sector. Unless critical unsustainable practices are brought to the consumers' attention by pressure groups, it could be the case of business as usual for the palm industry.

\section{References}

Aini, I. N. \& Miskandar, M. S. (2007). Utilization of palm oil and palm products in shortenings and margarines. European Journal of Lipid Science and Technology. 109 (4), 422- 432.

Basiron, Y. \& Kook-Weng, C. (2004). The Oil Palm and its Sustainability. Journal of Oil Palm Research. 16 (1), 1-10. 
Block, B. (2009). Can "Sustainable" Palm Oil slow deforestation? [on-line] Worldwatch Institute. Available from: http:// www.worldwatch.org (Date accessed: 25/05/2015).

Bredahl, L. (2003). Cue utilisation and quality perception with regard to branded beef. Food Quality and Preference. Elsevier. 15, 65-75.

Bredahl, L., Grunter, K.G. \& Fertin, C. (1998). Relating consumer perceptions of pork quality to physical product characteristics. Food Quality and Preference. 9, 273-281.

Corley, R.H.V. \& Tinker, P.B. (2003). The Oil Palm. 4th ed. Blackwell Science.

De Pelsmacker, P. \& Janssens, W. (2007). A model of fair trade buying behaviour: the role of perceived quantity and quality of information and of product-specific attitudes. Journal of Business Ethics. 75 (4), 361-380.

Gee, P.T. (2007). Analytical characteristics of crude and refined palm oil and fractions. European Journal of Lipid Science and Technology. 109 (4), 373-379.

Gengler, C. \& Reynolds, T. (1995). "Consumer understanding and advertising strategy: analysis and strategic translation of laddering data. Journal of Advertising Research. 35 (4), 19-32.

Gellert, P.K. (2015), Palm Oil Expansion in Indonesia: Land Grabbing as Accumulation by Dispossession, in Jon Shefner (ed.) States and Citizens: Accommodation, Facilitation and Resistance to Globalization (Current Perspectives in Social Theory). Vol. 34, 65 - 99.

Gerber, J-F. (2011). Conflicts over industrial tree plantations in the south: who, how and why? Global Environmental change. 21 (1), 165 - 176. Elsevier.

Gunstone, F. D. (2011). Vegetable oils in food technology: composition, properties and use. $2^{\text {nd }}$ ed. Wiley - Blackwell.

Grunert, K.G., Bredahl, L. \& Brunso, K. (2004). Consumer perception of meat quality and implications for product development in the meat sector - a review. 66, 259-272.

Hickman, M. (2009). The guilty secrets of palm oil: Are you unwittingly contributing to the devastation of the rain forests? The Independent. May.

Olson J., \& Reynolds, T. (2001). Understanding Consumer Decision Making: The Means-End Approach to Marketing and Advertising Strategy. Lawrence Erlbaum Associates, Publishers.

Pye, O. \& Bhattacharya, J. (2013). The palm oil controversy in Southeast Asia: a transnational perspective. Institute of Southeast Asian Studies.

Rist, L., Feintrenie, L. \& Levang, P. (2010). The livelihood impacts of oil palm: smallholders in Indonesia. Biodiversity and conservation, 19 (4), 1009-1024. 
Wicke, B.; Sikkema, R.; Dornburg, V. \& Faaij, A. (2011). Exploring land use change and the role of palm oil production in Indonesia and Malaysia. Land Use Policy. 28 (1), 193-206. 